\title{
Effects of Horticultural Activity on the Job Satisfaction Classified by Working Women
}

\author{
Byung Jin Choi, Young Hee Choi, and Suk Young Yun* \\ Faculty of Environment, Horticulture and Landscaping, Daegu Catholic University. Gyeongsan 38430, South Korea
}

\begin{abstract}
The purpose of this study is to look into the effect of a horticultural activity program on career women's job satisfaction. As the research subject, this study set 37 career women of 6 occupational clusters, such as elementary school teachers, nurses, social workers, care teachers, and police officers in ' $\mathrm{P}$ ' city, and financiers in 'D'city. The horticultural activity program was applied for about 10 months from June 2013 to April 2014, and for each job group the program was executed once a week and a total of 8 sessions. As a result of the analysis of job satisfaction by conducting horticultural activity by 6 occupational cluster, occupational clusters like an elementary school teacher, and social worker showed a significant improvement in job satisfaction immediately after horticultural activity was conducted, and in 4 weeks after that, all 5 occupational clusters but a care teacher cluster were found not to show a significant difference. It is expected that various horticultural activity programs would provide emotional stability to working women and consequently improve their overall quality of life. As a result of the above research, this study confirmed that improvement in job satisfaction is more effective when a person steadily participates in gardening activity rather than doing gardening activity temporarily. In addition, this study confirmed that gardening activity could be an alternative remedy which provides a positive change to a career woman's job satisfaction.
\end{abstract}

Key words: alternative remedy, school teachers, social workers

\section{I . Introduction}

As women became more highly educated and the occupations have become more specialized and diversified, there was a rapid increase of women entering into the society, through which their role and status improved, and this must be understood not as a temporary phenomenon but an outcome of growth of national consciousness and economic development. Along with the increase in the number of working women, some researches began to study job stress and strategies to cope with stress. However, there is still not enough systematic research on female workers compared to that on male workers (Lee, 1999). Professional women working in various occupational clusters experience various kinds of job stress such as importance of the role as a worker, work overload, interpersonal relations, and role as a family member, and yet they are not coping with

Received on January 31, 2017. Revised on March 2, 2017.

Accepted on June 6, 2017.

*Comesponding author: yune1004@cu.ac.kr

This paper is funded by the research funds of Daegu Catholic University in 2014 such stress in a proper manner. Therefore, it is necessary to determine and alleviate the factors that affect job stress, and help workers feel more satisfied with their work.

Job satisfaction refers to pleasure or emotional satisfaction obtained by evaluating the job itself or the experience through the job, depending on individual attitude and value, belief, and needs. The level of job satisfaction is related to human needs, and the process of expressing this need in the form of behavior to fulfill it becomes the motivation. Therefore, motivation is the psychological state that mediates human needs and behaviors (Jeon, 2013).

Job satisfaction is important in terms of mental health, but it also affects physical health as dissatisfaction may cause stress (Park, 2008). People learn new things through horticultural activities and use related knowledge and technology to fulfill the need of pleasure through learning (Hwang, 2007). Plants are effective in providing joy and peace, stability, composure and happiness, and also in improving the quality of life (Son et al., 1997; Son, 2004). Yoon (2001) claimed that people tend to have a sense of responsibility in managing plants because they gain confidence by putting effort into the plants that will grow 
easily, or they neglect the plants and the plants will get ill or not grow properly. Moreover, the results of horticultural activities can also purify emotions by providing achievement and satisfaction.

Accordingly, this study was conducted to determine job satisfaction of working women and provide baseline data to find ways to improve job satisfaction and work efficiency with horticultural activities.

\section{Research method}

\section{Research subjects}

This study was conducted on total 37 working women categorized into 6 occupational clusters. The first cluster consisted of elementary school teachers with regular classes at elementary schools, and the second cluster consisted of nurses in charge of nursing at S General Hospital. The third cluster consisted of the directors and social workers at local children's centers in charge of social welfare, and the fourth cluster consisted of nursing teachers in charge of early childhood education at $\mathrm{H}$ Daycare Center. The fifth cluster consisted of police officers at $6 \mathrm{~N}$ Police Station, and the sixth cluster consisted of NH Bank employees located in D City. Table 1 shows the detailed characteristics of the subjects.

\section{Experimental design}

This study adopted the nonequivalent control group pretestposttest design. The experimental group had their job satisfaction equally measured before and after the horticultural activities. The control group only took measurements at the same time as the experimental group without the horticultural activities. This study also took another measurement 4 weeks after the program to determine the durability of the horticultural activities (Table 2)

\section{Research tool}

1) Design of the horticultural program

Producing something through various horticultural activities makes people feel joy and rewarded about achieving something (Son et al., 1997), and also feel the value of existence by

Table 1. Characteristics of 7 groups in this experiment.

\begin{tabular}{|c|c|c|c|c|c|}
\hline Occupation & Group & $\mathrm{N}$ & Sex & Average age & Average working years \\
\hline \multirow{2}{*}{ Elementary school teachers } & Cont. & 8 & $\mathrm{~F}$ & 53.6 & 30.5 \\
\hline & Exp. & 8 & $\mathrm{~F}$ & 57.3 & 28.4 \\
\hline \multirow{2}{*}{ Nurses } & Cont. & 7 & $\mathrm{~F}$ & 27.2 & 3.7 \\
\hline & Exp. & 6 & $\mathrm{~F}$ & 33.5 & 8.5 \\
\hline \multirow{2}{*}{ Social workers } & Cont. & 8 & $\mathrm{~F}$ & 46.8 & 3.9 \\
\hline & Exp. & 8 & $\mathrm{~F}$ & 47.9 & 3.2 \\
\hline \multirow{2}{*}{ Care teachers } & Cont. & 7 & $\mathrm{~F}$ & 31.4 & 4.2 \\
\hline & Exp. & 7 & $\mathrm{~F}$ & 38.4 & 6.5 \\
\hline \multirow{2}{*}{ Police officers } & Cont. & 8 & $\mathrm{~F}$ & 43.3 & 17.5 \\
\hline & Exp. & 7 & $\mathrm{~F}$ & 31.4 & 7.1 \\
\hline \multirow{2}{*}{ Financiers } & Cont. & 6 & $\mathrm{~F}$ & 36.6 & 10.6 \\
\hline & Exp. & 7 & $\mathrm{~F}$ & 36.7 & 16.0 \\
\hline
\end{tabular}

Table 2. Experimental design

\begin{tabular}{lcccc}
\hline Group & Before-test & Treatment & After-test & After 4 weeks-test \\
\hline Cont. & $\mathrm{C}_{1}$ & & $\mathrm{C}_{2}$ & $\mathrm{C}_{3}$ \\
Exp. & $\mathrm{E}_{1}$ & $\mathrm{HA}$ & $\mathrm{E}_{2}$ & $\mathrm{E}_{3}$ \\
\hline
\end{tabular}

$\mathrm{HA}=$ Horticultural Activity. 
offering the horticultural products to others as a gift (Williams and Anderson, 1991). Therefore, this study designed the program so that the participants can learn new horticultural skills through such activities and complete the outputs on their own while fulfilling the need for pleasure through learning, and give the outputs to others as a gift. Moreover, to reduce job stress, the program consisted of repeated cutting, tying, sticking, winding and bending, as well as simple skills like drawing and putting in a vase. Moreover, to improve job satisfaction, the subjects were also to recall the pleasant memories of the past (Kim, 2010). Table 3 shows the details of the horticultural program. Session 1 could expect an increase of one's decision making power by making a dish garden with the plants of their choice. In Session 2, the participants experienced the freedom of expression using various colors of sand. Session 3 consisted of hanging plants to understand the symbiosis of plants and to learn about mutual dependence and cooperation. In Session 4, the participants recalled their most memorable and beautiful moment and put that image in a frame, decorating it with dried flowers. Session 5 increased the satisfaction of the participants by cutting and putting various cut-flower materials in the same length. In Session 6, they could feel composure and relax in the exhausting daily life by putting some extra space for the pots and plants after planting cactus and succulent. In Session 7, they planted plants to increase confidence and self-esteem in the process of turning useless and discarded PET bottles into a wonderful flower pot. In Session 8, they created a collage using seeds, completing their presence in their works.

2) Implementation of the program

The program was carried out by the main therapist and researcher (horticulturalist (Level 1) of the Korean Horticultural Therapy Association) with the help of one assistant therapist. Total 8 sessions of the horticultural program were carried out one session each per week by occupation, and the participants in each occupation selected the time they felt most relaxed. Each session lasted 60 minutes, and the materials cost of the program for each session was about 10 thousand KRW on average.

\section{3) Assessment tool}

To determine the effects of horticultural activities on job satisfaction of working women, this study used the job satisfaction scale for assessment. The assessment tool used in this study consisted of 25 items in satisfaction by aspect and 26 single items about overall job satisfaction, with reference to the job satisfaction scale by Park (1993). Cronbach's $\alpha$ for reliability was 0.91 . The assessment was done by the participants in the form of self-report before and after the horticultural program, as well as 4 weeks after the program.

\section{4) Data analysis}

The effects of horticultural activities in this study were analyzed using IBM SPSS Statistics 19.0 program for the effects within the same occupational cluster, and the homogeneity testing of the control group and experimental group was carried out before the program using Mann-Whitney U test. To compare the difference in the average before, after and 4 weeks after the program in the control group and experimental group, repeated measures ANOVA was used for analysis.

Table 3. Horticultural activity program for this experiment

\begin{tabular}{cll}
\hline No. & \multicolumn{1}{c}{ Program } & \multicolumn{1}{c}{ Botanical name } \\
\hline 1 & O/T and dish garden & Euphorbia pulcherrima, Kalanchoe blossfeldiana, Fittonia verschaffeltii, Pteris cretrca \\
2 & Terrarium & Hoya carnosa \\
3 & Hanging plant & Hoya carnosa, Hedera chrysantha \\
4 & Art flower frame & Edgeworthia papyrifera, Actinidia arguta \\
5 & Cut flower topiary & Rosa hybrida, Dianthus caryophyllus \\
6 & Planting cactus and succulent & Haworthia fasciata, Aeonium decorum, Schlumbergera truncata \\
7 & Napkins craft planting & Hoya carnosa, Chlorophytum comosum \\
8 & Seed collage & Oryza sativa, Citrullus vulgaris, Glycine max, Lens culinaris, Vigna radiata \\
\hline
\end{tabular}




\section{Results and discussions}

\section{Intergroup homogeneity testing}

As a result of verifying job satisfaction with Mann-Whitney $\mathrm{U}$ test to determine homogeneity of the control group and experimental group before carrying out the horticultural program in the six occupational clusters, it was found that all clusters had no significant difference in the control group and experimental group (Table 4). This proved that the two groups are homogeneous in terms of job satisfaction.

\section{Intragroup pretest and posttest changes}

Repeated measures ANOVA was conducted to determine whether there are changes before, after and 4 weeks after the horticultural program in the six occupational clusters. In the control group, all occupational clusters except nurses had no significant differences before, after and 4 weeks after the program. Nurses, who are in health care with high job stress (Kim and Suh, 2011), showed a significant decrease in job satisfaction from 91.86 points before the program to 75.57 points after, and 71.00 points 4 weeks later. In the experimental group, all of nurses, social workers, nursing teachers, police officers and bankers showed a slight increase in job satisfaction scores, but with no statistically significant difference. On the other hand, elementary school teachers showed an increase from 122.00 points before the program to 144.50 after, and 131.25 points 4 weeks later, showing a significant difference $(p=.005)$ (Table 5).

With posteriori tests of the experimental group by occupation, this study determined the changes before, after and 4 weeks after the program. Job satisfaction increased right after the program than before, with the average difference value being negative in all occupational clusters. Durability after 4 weeks was maintained in all clusters except police officers and bankers, showing high scores compared to before. In particular, the result of the posteriori test showed that job satisfaction showed a significant increase in before and after of elementary school teachers ( $p=.036)$, before and after of social workers $(p=.034)$, and before and 4 weeks after of nursing teachers $(p=.027)$ (Table 6).

Nursing teachers showed a constant increase of job satisfaction even after the program. This result was similar to the study that they realized how to put in more affection and interest as they raise their own flower pots and seedlings, and felt confidence and achievement about care giving and harvesting through the horticultural activity (Son et al., 2006). Moreover, it is in line with the study that horticultural activities implementing reality therapy brought positive changes to the problemfocused coping of stress and parenting efficacy of the mothers of elementary school students (Hwang, 2007), and that their need for pleasure is fulfilled by obtaining new knowledge and skills through horticultural activities using green plants (Lee, 2007). Furthermore, the results support that their interpersonal relations are improved by various horticultural activities, and they realize the value of existence and feel joyful and rewarded in life (Son et al., 1997)

This study failed to sufficiently reflect the representative nature of samples in the sampling process since the subjects were not all working women but limited to only 6 occupational

Table 4. Homogeneity of control and experimental of all of six occupation before the experiment.

\begin{tabular}{|c|c|c|c|c|}
\hline Item & Occupation & $\begin{array}{l}\text { Cont. } \\
\text { (Score) }\end{array}$ & $\begin{array}{c}\text { Exp. } \\
\text { (Score) }\end{array}$ & $p$ \\
\hline \multirow{4}{*}{ Job satisfaction } & School teachers & $120.75 \pm 17.96$ & $122.00 \pm 12.90$ & $.793^{\mathrm{NS}}$ \\
\hline & Social worker & $116.50 \pm 17.57$ & $107.88 \pm 10.16$ & $.207^{\mathrm{NS}}$ \\
\hline & Care teachers & $103.14 \pm 5.64$ & $117.14 \pm 20.42$ & $.124^{\mathrm{NS}}$ \\
\hline & Financiers & $107.00 \pm 31.39$ & $114.86 \pm 21.93$ & $.352^{\mathrm{NS}}$ \\
\hline
\end{tabular}

Values are presented mean \pm standard deviation.

${ }^{\mathrm{NS}}$ Non-significant by Mann-whitney U test. 
Byung Jin Choi, Young Hee Choi, and Suk Young Yun

Table 5. Changes in job satisfaction of all of six occupation before, after, and after 4 weeks horticultural activity.

\begin{tabular}{|c|c|c|c|c|c|}
\hline Group & Occupation & $\begin{array}{l}\text { Before-HA } \\
\text { (Score) }\end{array}$ & $\begin{array}{l}\text { After-HA } \\
\text { (Score) }\end{array}$ & $\begin{array}{l}\text { After } 4 \text { weeks-HA } \\
\text { (Score) }\end{array}$ & $p$ \\
\hline \multirow{6}{*}{ Cont. } & School teachers & $120.75 \pm 17.96$ & $120.00 \pm 27.77$ & $109.00 \pm 29.38$ & $.628^{\mathrm{NS}}$ \\
\hline & Nurses & $91.86 \pm 7.63$ & $75.57 \pm 17.15$ & $71.00 \pm 23.35$ & $.042 *$ \\
\hline & Social worker & $116.50 \pm 17.57$ & $122.25 \pm 23.28$ & $116.88 \pm 14.65$ & $.794^{\mathrm{NS}}$ \\
\hline & Care teachers & $103.14 \pm 5.64$ & $102.29 \pm 12.57$ & $109.57 \pm 12.14$ & $.112^{\mathrm{NS}}$ \\
\hline & Police officers & $122.75 \pm 18.43$ & $124.75 \pm 23.66$ & $118.88 \pm 33.34$ & $.613^{\mathrm{NS}}$ \\
\hline & Financiers & $107.00 \pm 31.39$ & $120.67 \pm 31.81$ & $110.67 \pm 8.96$ & $.649^{\mathrm{NS}}$ \\
\hline \multirow{6}{*}{ Exp. } & School teachers & $122.00 \pm 12.90$ & $144.50 \pm 18.51$ & $131.25 \pm 21.84$ & $.005^{* *}$ \\
\hline & Nurses & $102.83 \pm 10.13$ & $108.50 \pm 11.15$ & $109.67 \pm 18.86$ & $.460^{\mathrm{NS}}$ \\
\hline & Social worker & $107.88 \pm 10.16$ & $117.88 \pm 14.44$ & $116.00 \pm 7.11$ & $.103^{\mathrm{NS}}$ \\
\hline & Care teachers & $117.14 \pm 20.42$ & $118.43 \pm 27.50$ & $127.14 \pm 21.87$ & $.073^{\mathrm{NS}}$ \\
\hline & Police officers & $106.43 \pm 9.48$ & $114.29 \pm 19.78$ & $105.57 \pm 12.19$ & $.336^{\mathrm{NS}}$ \\
\hline & Financiers & $114.86 \pm 21.93$ & $118.14 \pm 20.36$ & $105.14 \pm 10.98$ & $.165^{\mathrm{NS}}$ \\
\hline
\end{tabular}

Values are presented mean \pm standard deviation.

$\mathrm{HA}=$ Horticultural Activity.

${ }^{\text {NS }}$ Non-significant; $* p<.05, * * p<.01$ by repeated measures design ANOVA.

Table 6. Comparison by correspondence of experimental group.

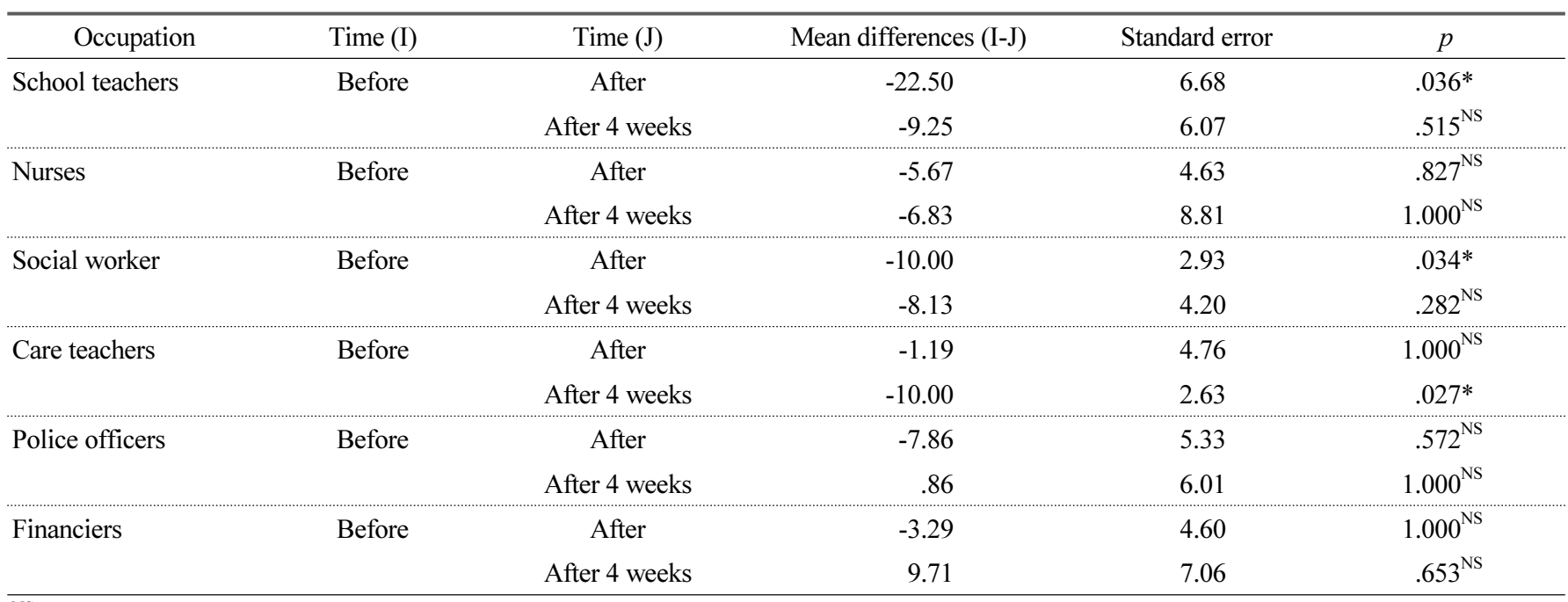

\footnotetext{
${ }^{\mathrm{NS}}$ Non-significant; ${ }^{*} p<.05$ by repeated measures design ANOVA.
}

clusters who wanted to participate in the horticultural activities. Therefore, there are limitations in generalizing the results of this study. A more extended research shall be conducted based on the International Standard Classification of Occupations to present the value of horticulture as a means to improve the overall quality of life while also bringing emotional stability to working women.

\section{Conclusion}

This study was conducted to determine the effects of horticultural activities on job satisfaction of working women. The subjects of this study were 37 working women in 6 occupational clusters such as elementary school teachers, nurses, social workers, nursing teachers and police officers in P City, and financiers in D City. The horticultural program 
went on for about 10 months from June 2013 to April 2014 in total 8 sessions, one session every week for each occupation. As a result of repeated measures ANOVA, only elementary school teachers among the six clusters showed an increase from 122.00 points before the program to 144.50 points after, and 131.25 points after 4 weeks, showing a significant difference $(p=.005)$. Moreover, in the posteriori test comparison, job satisfaction significantly increased after the horticultural activities for elementary school teachers $(p=.036)$ and social workers $(p=.034)$, while durability after 4 weeks had a significant difference only for nursing teachers. Therefore, a variety of horticultural programs are expected to improve the overall quality of life by providing emotional stability to working women. The results above proved that constant participation in horticultural activities is more effective in improving job satisfaction than temporary participation, and that horticultural activities can be an alternative remedy that brings positive changes to job satisfaction of working women.

\section{References}

Hwang, H.J. 2007. Effect of horticultural therapy based upon reality therapy on the reduction of depression the change in parental sense of competence and stress coping types of elementary student's mother. MS Thesis, Konkuk Univ., Seoul, Korea.

Jeon, H.S. 2013. The influences of elementary teacher's perceived organizational conflict on job satisfaction and job involvement: Mediating effect of teacher efficacy. MS Thesis, Kyungsung Univ., Busan, Korea.
Kim, M.L. 2010. Effects of horticultural therapy program with reminiscence on the elderly with chronic diseases focusing on ego integrity and self-esteem. MS Thesis, Uiduk Univ., Gyeongju,, Korea.

Kim, Y.H. and K.C. Suh. 2011. Relationships between job stresses, ego-resilience, stress responses, and quality of service among hospital employees. Korean J. Health Psychol. 16(2):329-345.

Lee, D.S. 1999. A study of development and standardization to measure job stress in Korea. PhD. Diss., Hallym Univ., Chuncheon, Korea.

Lee, Y.A. 2007. Effect of horticultural therapy using pressed flower based upon logotherapy on the improvement of the purpose in life and ego identity of middle-aged women. MS Thesis, Konkuk Univ., Seoul, Korea.

Park. B.Y. 2008. A study on the job satisfaction of educational administrative staff. MS Thesis, Kumoh Natl. Univ. Technol., Gumi, Korea.

Park, S.Y. 1993. The relationships among components of equity, job satisfaction and turnover intention. PhD. Diss., Sungkyunkwan Univ., Seoul, Korea.

Son, K.C. 2004. Horticultural healing. Seoul, Korea: Joongangsaenghwal Press.

Son, K.C., S.K. Park, H.O. Boo, K.Y. Paek, K.Y. Bae, S.H. Lee, and B.G. Huh. 1997. Horticultural therapy. Seoul, Korea: Seowon Press. .

Son, K.C, S.Y. Kim, S.S. Lee, J.E. Song, and M.G. Jo. 2006. Programs and assessment tools for the professional horticultural therapy. Seoul, Korea: Kubuk. .

Willianms, L.J. and S.E. Anderson. 1991. Job satisfaction and organizational commitment as predictors of organizational citizen ship and in-role behaviors. J. Manag. 17(3):601-617. DOI: 10.1177/ 014920639101700305

Yoon, S.K. 2001. The effect of the plant-culture working on changes in children's personality. MS Thesis, Seoul Natl. Univ. Educ., Seoul, Korea. 